\title{
Reconstruction of the Computer Hardware Curriculum
}

\author{
Ding SHEN, Fang LI and Sheng-ju SANG \\ School of Information Science and Technology \\ Taishan University \\ Taian Shandong, China, 271000 \\ Corresponding author:sang1108@163.com
}

\author{
Yue-ying WU \\ School of Mathematics and Statistics \\ Taishan University \\ Taian Shandong, China, 271000 \\ wyy7758525@126.com
}

\author{
Yue-ying WU \\ School of Information Science and Technology \\ Qingdao University of Science and Technology \\ Qingdao, Shandong, China, 266061 \\ Corresponding author:wyy7758525@126.com
}

\begin{abstract}
This paper demonstrates a thoroughly innovative research on reconstruction of the curriculum of computer hardware. The curriculum practice, to some appropriate extent, brings together 'topical case studies', 'class projects', and 'study an d engineering work in industry' activities throughout the teaching progress. This research provides a broad background in computer engineering concepts and enhanced teaching practice that could meet requirements from a wide range of industries and organiza tions.
\end{abstract}

Keywords-Reconstruction; computer hardware; curriculum system.

\section{INTRODUCTION}

The original course hierarchy is not suitable for the goals of all colleges [1,2]. Foreign universities, like MIT, UC Berkley, Stanford, MCUs have setup computer curriculum with special features [7-9]. The Computer Science and Technology Teaching Steering Committee of the Ministry of Education of China proposes the direction of computer disciplinary development with the spirit of "classified educational specification" and encourages universities providing various types of curriculum plans[3] based on both social exceptions and available resources[4,5]. More and more university in China have made some progress on such kind of research and brought forward practice plans on curriculum, contents and laboratories [6].

\section{CURRICULUM OF COMPUTER HARDWARE}

The goal focuses on computer applications to meet real engineering activities which not only include broad theories, but problem-solving techniques in engineering. According to this goal, this paper optimizes the original courses 'Computer Organization', 'Principle of Mini-computer', 'Principle of MCU', 'and Computer Architecture' in undergraduate phase; setup both the teaching arrangement and curriculum for computer hardware knowledge base. Lecture hours allocation is shown in table 1.

\section{KNOWLEDGE STRUCTURE OF COMPUTER HARDWARE COURSE}

The optimization of this curriculum is exemplified with below changes in the course of 'Principle of Computer Organization' and 'Mini-computer Interfaces technology'.

In the course of 'Principle of Computer Organization', there are detailed explanations on microcode working principles, structures, design of logics inside controllers and accumulators. These are basic knowledge for processor designer and researchers, but for computer applications, who cares at most about processor features and programmable registers, the internal structure details could be seen as a 'black box'.

And in the teaching practice of 'Mini-computer Interface Technologies', the $8086 / 8088$ assembly programming could be simplified; the legacy parallel interface chips learning could be shorten; for important concepts like DMA, just focuses on its principles; and for other chipset features, only a brief introduction. These changes impacts little on the undergraduates' ability preparations as the legacy parallel chips and 8086/8088 assembly are almost unavailable in real applications. We could put the bus, memory related contents into the 8051-chip sub-system context; not only for its simplicity, but straight forward and easy to understand and grasp the spirits. 
TABLE I. LECTURE HOUR'S ALLOCATION OF COMPUTER HARDWARE COURSE

\begin{tabular}{|c|c|c|c|c|c|c|}
\hline \multirow{2}{*}{ Courses } & \multirow{2}{*}{ Type } & \multirow{2}{*}{ Credit } & \multicolumn{3}{|c|}{ Class hours } & \multirow{2}{*}{ Semester } \\
\hline & & & Total & Theory & Experiment & \\
\hline Introduction to Computer Science & Compulsory & 5 & 80 & 44 & 36 & 1 \\
\hline Computer Circuit & Compulsory & 5 & 96 & 78 & 18 & 2 \\
\hline Computer system architecture (1) & Compulsory & 4 & 72 & 54 & 18 & 3 \\
\hline Computer system architecture (2) & Compulsory & 4 & 72 & 54 & 18 & 4 \\
\hline Computer network & Optional & 3 & 54 & 36 & 18 & 5 \\
\hline Principle of MCU & Optional & 3 & 54 & 36 & 18 & 5 \\
\hline Computer system design & Optional & 3 & 54 & 36 & 18 & 6 \\
\hline Embedded system & Optional & 3 & 54 & 42 & 12 & 6 \\
\hline Internet of things technology & Optional & 3 & 54 & 42 & 12 & 6 \\
\hline Computer Comprehensive Design & Compulsory & 4 & 72 & 20 & 50 & 7 \\
\hline
\end{tabular}

\section{CONTENTS OF TEACHING IN COMPUTER HARDWARE CURRICULUM}

Some contents appear in multiple courses in computer hardware and teachers usually explain them from the perspective of each course. This forms the fact that for one knowledge unit, many teachers mentioned, but no one gives a clear description, which makes students feel dull and negates learning interests.

\section{A. Construction of Computer Hardware Basics Course}

'Computer Hardware Basics' integrates knowledge's units from courses 'Circuit Basics', 'Analog Circuit' and 'Digital Circuit' By taking this course, students are expected to grasp basic concepts of circuits and electrical quantities and elements, as well as the analysis and design of simple electronic circuits using appropriate techniques.

These contents encompass basics in hardware circuits and make solid foundation for the counterpart in later courses 'Principle of Computer Organization', 'Mini-computer Interface Technologies' and 'Computer Architectures' to give students a full view of computer hardwires. This integration also emphasizes the pillar role of digital logic circuits which is consistent with current trend of VLSI digital logic circuits and the goal of preparing employment-oriented professional skills for undergraduates.

During the concrete practice, we abandoned and augmented some contents based on professional features and preparation goals, tried our best to fulfill the practice of 'Computer Hardware Basics' to make knowledge applied.

\section{B. Optimization of 'Computer Architectures' Course}

This course integrates contents in original 'Computer Organization', 'Assembly Programming', 'Principle of Mini-computer', 'Computer Architecture' and extends application practices. This course introduces basic concepts of computer ALU, host controller, memory and I/O; also the memory hierarchy, bus, instruction set, interrupt and assembly programming including common I/O. The whole course could be categorized into two parts: Computer Architectures one (CA1) and Computer Architectures two (CA2).

\section{ElECTIVE CURRICULUM IN COMPUTER HARDWARE}

To meet various personal interests of students and the profession realm, the undergraduate computer hardware courses should also include 'Principle of MCU', 'Embedded System Design', 'Computer Organization', 'Computer Network', 'Internet of things technology', etc. These courses could enhance students' cognation of computer system and setup a better foundation for future career development planning.

\section{A. Principle of $M C U$}

MCU technology is taken seriously by colleges and industries. This course, as an important elective in computer related department, the teaching spirit of which is: the goal of focusing on basic knowledge to prepare for practice and utilization of such knowledge, the creativity and acquiring more during such a process.

\section{B. Embedded System Design}

It is embedded as part of a complete device often including hardware and mechanical parts. Embedded systems control many devices in common use today, from music player to astronaut satellite systems. Setting up this course could not only provide a 
chance for students to get in touch with more advanced computer architecture trends, but enhance their problem-solving abilities with real embedded system products.

\section{Internet of Things Technology (IoT)}

With the background of other computer hardware courses, students could exercise in the data labeling, acquisition, transmission, recognition and control, also the practice of system integration and IoT engineering which could be beneficial for them to become professionals with high-caliber that could adapt to the development of those strategic emerging industries.

\section{Computer Organization Design}

This course inspects and evaluates the design and function allocations in a particular computer system and its performance indicators.

\section{E. Computer Network}

This course introduces basic theories of network technology and common network devices which was separated into different courses before. TCP/IP network stack is a main part of contents. The learning outcome is to master the setup and maintenance techniques of LAN and Internet and some practical networking techniques.

\section{SUMMARY}

The new 'Computer Hardware Basics' and 'Computer Architectures' simplify some complex concepts and give students a easyto-understand whole picture of computer, also with new technologies in this area. Meanwhile, according to students' interest and professional realms, the elective courses like 'Principle of MCU', "Embedded System Design", etc. are setup. The reconstruction could be used extensively and it could bring enhanced cognitions of computer system, more practice in system integration and application and better preparation for qualified professionals that could adapt to emerging industries.

\section{ACKNOWLEDGEMENT}

The Research was partially supported by "The reform and Practice Research of computer hardware basic course system of Applied Undergraduate Course" of the Research project on teaching reform of Shandong Provincial Education Department, China (NO. LU JIAO GAO WEN 2015-12), the science and technology development fund of Tai' an (No. 20133011, 201320629 and 2016GX0004), and the Foundation provided by Taishan University (no.Y-01-2013010). The authors also thank the associate editor and the anonymous reviewers for their valuable comments.

\section{REFERENCES}

[1] ACM/AIS/IEEE-CS, Computing Curricula 2005[OL/S], http://www.acm.org/education/curric_vols/CC2005- March 06 Final.pdf.

[2] Nanjing University teaching system, [EB/OL].http://software.nju.edu.cn/ index.php option= com_content \& view=article\&id= 146\&Itemid= 4/.(In Chinese)

[3] TANG Zhiqiang, ZHU Zicong. Reform and innovation of digital logic curriculum for coputer sciece major, Computer Engineering \& science, 2014, (S2):159-161.

[4] Zhang L B, Zhang F, Luo T J. Knowledge structure evolution and evaluation method in computer science. Journal of University of Chinese Academy of Sciences, 2016, 33( 6) : 844-850. (In Chinese)

[5] SANG Sheng-ju \& SHEN Ding. Principle and application of microcontroller. Beijing: China Railway Publishing House, 2010:2-10. (In Chinese)

[6] FENG Weijian. Study on the reform of computer major course system in university. Journal of Hunan City University, 2016, (03): 265-266. (In Chinese)

[7] MIT. Computer Systems Engineering [EB/OL].Spring 2014.http://web.mit.edu /6.33/www/ index.shtml/.

[8] Stanford University. Computer organization and systems. [EB/OL].Spring 2012. http://www.stanford.edu/class/cs107/.

[9] CMU. Introduction to computer systems. [EB/OL]. Fall2014.http://www.cs.cmu. edu/ 213/. 